\title{
Bioequivalence: aspects beyond the pharmaceutical issues
}

\section{Short communication}

Bioequivalence $^{1,2}$ represents an important concept in pharmacy and pharmacology since it defines the similarity in term of both pharmacodynamic and pharmacokinetics. It represents the scientific concept that can insure the therapeutic equivalence of substitutive forms of the same treatments. However, the aspects related to the bioequivalence are not limited to the scientific definitions but are also influenced by factors none related to pharmacy and some of these factors should not even exist. Indeed, some drugs or pharmaceutical preparations that are supposed bioequivalent are in fact not equivalent. This might be due to either the process of bioequivalence validation or the quality control. In some countries/regions the drugs quality control systems are weak because of many reasons such as the relatively lack of sophisticated equipment and the limited number of experts. Another issue that seriously influences the quality of the bioequivalent drugs is represented by the administrative problems. For example, if the regulations are not severely applied we might find ourselves with an analytic document that certifies that two drugs are equivalent while they are not; this might be due to economic or political reasons which will have an impact of the population health.

Therefore, a good quality control system needs both an appropriate scientific approaches ${ }^{3-5}$ which implies an adequate training of professionals, and also laws and regulation with a server application of them toward putting the population health over the economic consideration. The implementation of such principles might require strong political decisions and eventually collaborations between different organizations within the same country, within a region and at an international level within the contexts of both international prescriptions $^{6}$ and international drug markets. ${ }^{7}$ Importantly, educating the general population (for example within the context of associations) about the bioequivalence-related concepts and make a general debate about them would put more pressure on health responsible toward improving the diver's medical and political aspects or the bioequivalence.

\section{Acknowledgements}

None.

\section{Conflict of interest}

The author declares no conflict of interest.
Volume I Issue 2 - 2015

\author{
Abdelaziz Ghanemi ${ }^{1,2}$ \\ 'Key Laboratory of Animal Models and Human Disease \\ Mechanisms of the Chinese Academy of Sciences \& Yunnan \\ Province, Chinese Academy of Sciences, China \\ ${ }^{2}$ Kunming College of Life Science, University of Chinese \\ Academy of Sciences, China
}

Correspondence: Abdelaziz Ghanemi, Key Laboratory of Animal Models and Human Disease Mechanisms, Kunming Institute of Zoology Chinese Academy of Sciences, No. 32 Jiaochang Dong lu, Kunming 650223, China, Email ghanemiabdelaziz@hotmail.com

Received: July II, 2015 | Published: July 25, 2015

\section{References}

1. Zhu H, Zhou H, Seitz K. Bioavailability and Bioequivalence. In: Qiu Y, Chen Y, Zhang GGZ, Liu L and Porter WR, editors. Developing Solid Oral Dosage Forms. USA: Academic Press; 2009. p. 341-364.

2. Powell ML. Absorption and bioequivalence. In: Thomas RB, editor. Pharmacochemistry Library. Elsevier. 1997;26:243-259.

3. Cuesta-Gragera A, Navarro-Fontestad C, Mangas-Sanjuan V, et al. Semi-physiologic model validation and bioequivalence trials simulation to select the best analyte for acetylsalicylic acid. European Journal of Pharmaceutical Sciences. 2015;74:86-94.

4. Rezk MR, Basalious EB, Karim IA, et al. Development of a sensitive UPLC-ESI-MS/MS method for quantification of sofosbuvir and its metabolite, GS-331007, in human plasma: Application to a bioequivalence study. Journal of Pharmaceutical and Biomedical Analysis. 2015;114:97-104.

5. Mei C, Li B, Yin Q, et al. Liquid chromatography-tandem mass spectrometry for the quantification of flurbiprofen in human plasma and its application in a study of bioequivalence. J Chromatogr B Analyt Technol Biomed Life Sci. 2015;(993-994):69-74.

6. Ghanemi A. Toward the concept of "standardized" international prescriptions. Res Social Adm Pharm. 2015;11(4):588-589.

7. Ghanemi A. International drugs markets database to improve global drugs accessibility. Research in Social and Administrative Pharmacy. 2017;13(4):880-881. 